\title{
ВОЗМОЖНОСТИ МР-ТРАКТОГРАФИИ В ОЦЕНКЕ ПОРАЖЕНИЯ ПРОВОДЯЩИХ ПУТЕЙ ПРИ УМЕРЕННО-КОГНИТИВНЫХ РАССТРОЙСТВАХ НА ФОНЕ ХРОНИЧЕСКОЙ ИШЕМИИ МОЗГА
}

\author{
${ }^{1}$ Маджидова Ё.Н.*, ${ }^{2}$ Ходжаева Д.Т., ${ }^{2}$ Хайдарова Д.К., ${ }^{3}$ Хайдаров Н.К. \\ ${ }^{\prime}$ Ташкентский педиатрический медииинский институт, Ташкент, Узбекистан; \\ ${ }^{2}$ Бухарский медицинский государственный институт, Бухара, Узбекистан \\ ${ }^{3}$ Ташкентская медиииская академия, Ташкент, Узбекистан
}

Достоверное снижение коэффициента фракционной анизотропии у больных хронической ишемией мозга с умеренными когнитивными расстройствами, особенно в белом веществе лобных долей служит доказательством начинающегося нейродегенеративного процесса в головном мозге, который в дальнейшем может трансформироваться в ту или иную форму деменции. Последнее может свидетельствовать о необходимости проведения МРтрактографии всем больным с когнитивными расстройствами, что в свою очередь позволит улучшить раннюю диагностику различных форм деменций.

Ключевые слова: хроническая ишемия мозга, когнитивные расстройства, трактография.

Сосудистые заболевания головного мозга в связи с широкой распространённостью, ростом показателей смертности и инвалидизации, являются важнейшей медико-социальной проблемой. Проблема хронической ишемии мозга (ХИМ) выдвигается на одно из ведущих мест современной ангионеврологии [2]. К ХИМ относятся начальные проявление недостаточности кровоснабжения мозга и дисциркуляторная энцефалопатия, которые с одной стороны, являются фактором риска развития инсульта, а с другой - причиной постепенного нарастания неврологических и когнитивных расстройств. Поскольку когнитивные функции связаны с интегрированной деятельностью головного мозга в целом, когнитивная недостаточность закономерно развивается при самых разнообразных очаговых и диффузных поражениях головного мозга [3].

Нейровизуализация определена как важный этап диагностики данной патологии, являясь незаменимым инструментом для дифференциации вещества мозга, определения этиологического диагноза, прогноза и тактики лечения [1].

Наибольший интерес среди исследователей в диагностике ХИМ вызывает МРТ. Появление новой методики на основе магнитного резонанса - диффузионной тензорной МР-трактографии - подтолкнуло отечественных и зарубежных исследователей к активно- му изучению её возможностей в оценке микроструктурных свойств белого вещества головного мозга [4].

Однако, опыт применения МР-трактографии в диагностике ХИМ в отечественной литературе практически отсутствует. Вместе с тем, зарубежные авторы сходятся во мнении, что эта методика способна дополнить объем и качество получаемой диагностической информации $[1,5]$. Следует отметить, что среди зарубежных ученых также нет единого мнения о возможностях количественной МРтрактографии в диагностике и прогнозе развития УКР при ХИМ.

Цель исследования - изучить показатели МР-тактографии у больных ХИМ и с различными типами УКР.

Материалы и методы исследования. Нами изучены МРТ 60 больных с хронической ишемией головного мозга сопровождавшейся умеренными когнитивными расстройствами (УКР). Больные распределены на две группы 34 больных с умеренными когнитивными потенциалами амнестического типа (УКР I) и 26 больных с умеренными когнитивными потенциалами мультифункционального типа (УКР II). Группу сравнения составили 12 человек сопоставимые по возрасту без проявлений когнитивных нарушений.

МРТ-исследование проведено на томографе PHILIPS с индукцией магнитного поля 1,5 Тл. Протокол исследований включал стан-

*e-mail:madjidova1@yandex.ru 
дартные программы (TISE, T2SE, FLAIR), a также прицельную визуализацию медиобазальных отделов височных долей с возможностью постпроцессинговой обработки и получением изображений в различных плоскостях. В всех случаях были получены диффузионно-тензорные изображения, которые обсчитывались с использованием встроенной постпроцессорной программы (Neuro 3D), которая включала построение карт фракционной анизотропии, измеряемого коэффициента диффузии, диффузионного тензора и реконструкцию проводящих путей в трехмерном режиме (трактографию). Дополнительно рассчитывались значения фракционной анизотропии (ФА).

Результаты исследования. Анализ изменений фракционной анизотропии в группе больных УКР І показал специфичность распределения зон с пониженной анизотрофией.
Так в данной группе больных нами выявлено снижение анизотрофии в переднем бедре внутренней капсулы, белом веществе лобных долей, мозолистом теле и базальных ядрах (таламус, черная субстанция. Снижение фракционной анизотропии наблюдалось по двигательным путям и проводникам экстрапирамидной системы, тогда как аналогичных изменений в чувствительных путях не отмечалось.

При изучении МР трактограмм больных группы УКР II нами выявлено снижение фракционной анизотропии в белом веществе лобных долей, таламусе, мозолистом теле, варолиевом мосту и черной субстанции.

Для определения степени выраженности изменений белого вещества в указанных зонах был измерен коэффициент фракционной анизотропии. Результаты представлены в таблице 1.

Таблица 1

Сравнительный анализ показателей фракционной анизотропии у больных с УКР на фоне ХИМ

\begin{tabular}{|l|c|c|c|}
\hline & Группа УКР I (n=34) & Группа УКР II (n=26) & $\begin{array}{c}\text { Группа контроля } \\
(\mathrm{n}=12)\end{array}$ \\
\hline $\begin{array}{l}\text { Белое вещество лобных } \\
\text { долей }\end{array}$ & $0,416 \pm 0,012^{*}$ & $0,412 \pm 0,011^{*}$ & $0,453 \pm 0,012$ \\
\hline Мозолистое тело & $0,738 \pm 0,014$ & $0,644 \pm 0,051$ & $0,788 \pm 0,021$ \\
\hline Полуовальный центр & $0,467 \pm 0,072$ & $0,358 \pm 0,027$ & $0,476 \pm 0,050$ \\
\hline $\begin{array}{l}\text { Нижний продольный } \\
\text { пучок } \\
\text { Таламус }\end{array}$ & $0,449 \pm 0,048$ & $0,447 \pm 0,039$ & $0,451 \pm 0,038$ \\
\hline
\end{tabular}

Примечание: *достоверные отличия с группой контроля $(\mathbf{p}<0,05)$.

При сопоставлении оценок по шкалам оценки психологического, нейропсихологического статуса и показателей коэффициента фракционной анизотропии между ними обнаружена статистически значимая корреляция.

Снижение коэффициента фракционной анизотропии, выявленное в белом веществе лобных долей и мозолистого тела, выраженное в процентном соотношении больше (до $9,1 \%$ и $8,2 \%$ соответственно), чем в других 3онах интереса, свидетельствует о риске развития нейродегенеративного процесса в этих структурах, которые по данным многих авторов являются основным звеном в патогенезе болезни Альцгеймера, и других нейродегенеративных процессов.

Заключение. Резюмируя полученные результаты нейровизуализационных исследований, можно сделать вывод о наличие у пациентов обеих групп (УКР I и УКР II) начинающегося нейродегенеративного процесса. Он выражается не только в расширении желудочковой системы, что характеризовалось в увеличении соотношения Эванса, индекса передних рогов, но и в снижении фракционной анизотропии, которая отражает заинтересованность белого вещества головного мозга. 


\section{ЛИТЕРАТУРА}

1. Ефимцев, А. Ю. Трактография как новый метод изучения патогенеза и дифференциальной диагностики деменций / А. Ю. Ефимцев и др. // Вестник Российской Военно-медицинской академии.- СПб. - 2009. - №4(28). - C. 56-57.

2. Котова О.В., Акарачкова Е.С. Хроническая ишемия головного мозга: патогенетические механизмы и принципы лечения. Фарматека 2010; №8(202): 57-61

3. Локшина А. Б. Легкие и умеренные когнитивные расстройства при дисциркуляторной энцефалопатии.
Дисс.. канд. мед. наук. - М., 2005. - 138 с.

4. Труфанов, Г. Е. Возможности количественной диффузионной тензорной магнитно-резонансной трактографии в диагностике неопухолевых заболеваний головного мозга / Г. Е. Труфанов, В. А. Фокин, А. Ю. Ефимцев и др. // Вестник Российской Военно-медицинской академии. - СПб. - 2009. - №3(27). - С. 145-151. 5. Basser P.J., Pajevic S., Pierpaoli C. et al. In vivo fiber tractography using DT-MRI data / Magn. Reson. Med, 2000; 44: 625-632.

\title{
XÜLASə
}

\section{BEYININ XRONIKİ İŞEMIIYASI FONUNDA MÜLAYIM KOQNITIV POZULMALAR ZAMANI APARICI YOLLARIN ZӘDӘLӘNMӘSININ QIYMӘTLONDIRILMӘSINDӘ MR-TRAKTOQRAFIYANIN IMKANLARI}

\author{
${ }^{1}$ Məcidova Y.N., ${ }^{2}$ Xocayeva D.T., ${ }^{2}$ Xaydarova D.K., ${ }^{3}$ Xaydarova N.K. \\ ${ }^{\prime}$ Daşkənd pediatrik tibb institutu, Daşkənd, Özbəkistan; \\ ${ }^{2}$ Buxara dövlat tibb institutu, Buxara, Özbəkistan; \\ ${ }^{3}$ Daşkənd tibb akademiyasl, Daşkənd, Özbəkistan
}

Mülayim koqnitiv pozulmalarla xroniki beyin işemiyası olan xəstələrdə əsasən də alın paylarının ağ maddəsində olmaqla, fraksion anizotropiyanın koeffisientinin dürüst enməsi, sonradan demensiyanın bu və ya digər formasına transformasiya oluna bilən baş beyində başlanan neyrodegenerativ prosesə dəlalət edir. Bu fakt koqnitiv pozulmaları olan xəstələrin hamısına MR-traktoqrafiyanın aparılmasının vacibliyini göstərə bilər ki, bu da demensiyanın müxtəlif formalarının erkən diaqnostikasının yaxşılaşmasına səbəb ola bilər.

Açar sözlər: beyinin xroniki işümiyası, koqnitiv pozulmalar, traktoqrafiya.

\section{SUMMARY}

\section{POSSIBILITY OF MR TRACTOGRAPHY IN EVALUATION OF PATHWAYS AT MODERATE-COGNITIVE DISORDERS WITH CHRONIC CEREBRAL ISCHEMIA}

\author{
${ }^{1}$ Majidova Yo.N., ${ }^{2}$ Khodjaeva D.T., ${ }^{2}$ Khaydarova D.K., ${ }^{3}$ Khaydarov N.K. \\ ${ }^{1}$ Tashkent Pediatric Medical Institute, Tashkent, Uzbekistan; \\ ${ }^{2}$ Bukhara State Medical institut, Bukhara, Uzbekistan \\ ${ }^{3}$ Tashkent Medical Academy, Tashkent, Uzbekistan
}

\begin{abstract}
A significant decline in the fractional anisotropy in patients with chronic cerebral ischemia with mild cognitive disorders, especially in the white matter of the frontal lobes is proof starting neurodegenerative process in the brain, which can later be transformed into one or another form of dementia. The latter may indicate a need for MR tractography in all patients with cognitive impairment, which in turn will improve the early diagnosis of various forms of dementia.
\end{abstract}

Keywords: chronic cerebral ischemia, cognitive disorders, tractography.

Redaksiyaya daxil olub: 19.10.2015

Çapa tövsiya olunub: 06.11.2015

Rayçi: Prof. Şiraliyeva R.K. 